\title{
Interaction of Linear Polyelectrolytes with Proteins: Role of Specific Charge-Charge Interaction and Ionic Strength
}

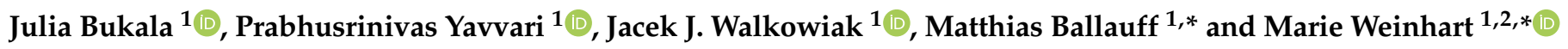 \\ 1 Department of Chemistry and Biochemistry, Freie Universität Berlin, Takustrasse 3, 14109 Berlin, Germany; \\ juliabukala@hotmail.com (J.B.); pyavvari@zedat.fu-berlin.de (P.Y.); jjwalkowiak@zedat.fu-berlin.de (J.J.W.) \\ 2 Institute of Physical Chemistry and Electrochemistry, Leibniz Universität Hannover, Callinstr. 3A, \\ 30167 Hanover, Germany \\ * Correspondence: mballauff@zedat.fu-berlin.de (M.B.); marie.weinhart@fu-berlin.de or \\ marie.weinhart@pci.uni-hannover.de (M.W.); Tel.: +49-30-838-75050 (M.B. \& M.W.)
}

Citation: Bukala, J.; Yavvari, P.; Walkowiak, J.J.; Ballauff, M.; Weinhart, M. Interaction of Linear Polyelectrolytes with Proteins: Role of Specific Charge-Charge Interaction and Ionic Strength. Biomolecules 2021, 11, 1377. https://doi.org/10.3390/ biom11091377

Academic Editor: Hidetaka Torigoe

Received: 16 August 2021

Accepted: 13 September 2021

Published: 17 September 2021

Publisher's Note: MDPI stays neutral with regard to jurisdictional claims in published maps and institutional affiliations.

Copyright: (c) 2021 by the authors. Licensee MDPI, Basel, Switzerland. This article is an open access article distributed under the terms and conditions of the Creative Commons Attribution (CC BY) license (https:/ / creativecommons.org/licenses/by/ $4.0 /)$.

\begin{abstract}
We present a thermodynamic study of the interaction of synthetic, linear polyelectrolytes with bovine serum albumin (BSA). All polyelectrolytes are based on poly(allyl glycidyl ether) which has been modified by polymer-analogous reaction with anionic $\left(-\mathrm{SO}_{3} \mathrm{Na}\right)$, cationic $\left(-\mathrm{NH}_{3} \mathrm{Cl}\right.$ or $\left.-\mathrm{NHMe}_{2} \mathrm{Cl}\right)$ or zwitterionic groups $\left(-\mathrm{NMe}_{2}\left(\mathrm{CH}_{2}\right)_{3} \mathrm{SO}_{3}\right)$. While the anionic polymer shows a very weak interaction, the zwitterionic polymer exhibits no interaction with BSA $(\mathrm{pI}=4.7)$ under the applied $\mathrm{pH}=7.4$, ionic strength $(\mathrm{I}=23-80 \mathrm{mM})$ and temperature conditions $\left(\mathrm{T}=20-37^{\circ} \mathrm{C}\right)$. A strong binding, however, was observed for the polycations bearing primary amino or tertiary dimethyl amino groups, which could be analysed in detail by isothermal titration calorimetry (ITC). The analysis was done using an expression which describes the free energy of binding, $\Delta G_{\mathrm{b}}$, as the function of the two decisive variables, temperature, $T$, and salt concentration, $c_{\mathrm{s}}$. The underlying model splits $\Delta G_{\mathrm{b}}$ into a term related to counterion release and a term related to water release. While the number of released counter ions is similar for both systems, the release of bound water is more important for the primary amine compared to the tertiary $N, N$-dimethyl amine presenting polymer. This finding is further traced back to a closer contact of the polymers' protonated primary amino groups in the complex with oppositely charged moieties of BSA as compared to the bulkier protonated tertiary amine groups. We thus present an investigation that quantifies both driving forces for electrostatic binding, namely counterion release and change of hydration, which contribute to a deeper understanding with direct impact on future advancements in the biomedical field.
\end{abstract}

Keywords: polycation; ITC; complex formation; counterion release; thermodynamic analysis

\section{Introduction}

Linear polyelectrolytes may form well-defined complexes with proteins in dilute solution. Thus, DNA, RNA, and other natural polyelectrolytes can interact with proteins such as polymerases in aqueous solution, and the complex formation presents a process that has been studied for decades [1]. The obvious biological importance has led to a large number of precise thermodynamic studies [2-11] that have been reviewed recently [12,13]. Synthetic polyelectrolytes interacting with proteins have also been the subject of intense studies [14-19]. The motivation for these investigations is two-fold: On the one hand, polymers are often appended to prevent the adsorption of proteins from aqueous solution [20]. On the other hand, polyelectrolytes may form complex coacervates [16] with proteins that have found various applications, e.g., in food technology [17].

Linear poly(glycidyl ether)s constitute a class of biocompatible polyethers with various applications in the biomedical field covering bioinert [21], antibacterial [22], celladhesive [23], as well as switchable [24] polymers and coatings. The functional side groups offer the possibility for further chemical modification and adjustment of the properties of these polyethers to the respective application $[25,26]$. Concerning cellular adhesion, a 
universal binding strategy is employed when designing biocompatible polycations which interact mainly electrostatically with the negatively charged cellular glycocalyx [27]. The safe use of such polymers for medical purposes requires a detailed and mechanistic understanding of their interaction with biological systems on all levels. For basic systematic studies, the versatile and efficient conversion of pending allyl groups of poly(allyl glycidyl ether) (PAGE) via thiol-ene chemistry generates a highly comparable set of polymers based on the same polyether backbone with adjustable functionalities [28]. Within the present study, we prepared a series of linear model polyelectrolytes (Figure 1) covering anionic, zwitterionic and cationic pendants to investigate their binding properties with proteins as one of the initial and fate-determining interactions in biological systems.

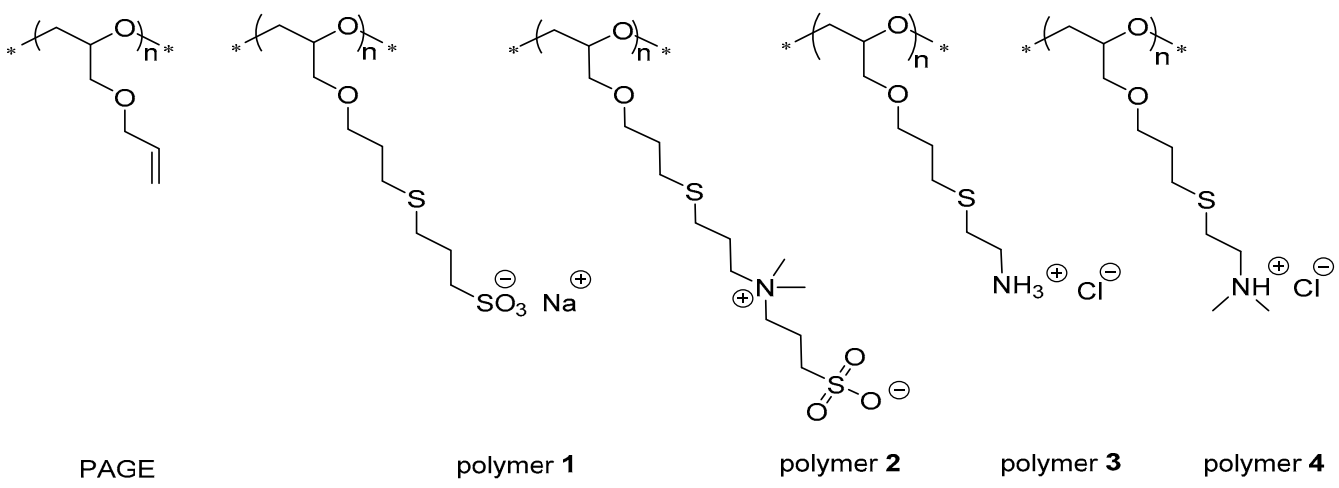

Figure 1. Chemical structure of the precursor poly(allyl glycidyl ether) (PAGE) from which the linear model polyelectrolytes 1-4 have been synthesized for investigation in this work (* denotes unspecified polymer end group).

At physiological $\mathrm{pH}$, the strong sulfonic acid groups of polymers $\mathbf{1}$ and $\mathbf{2}$ are deprotonated, yielding a polyanion and a neutral zwitterion, respectively, while both primary and tertiary amines in polymers 3 and 4 are largely protonated according to their $\mathrm{pK}_{\mathrm{a}}$ values. Albumin, as one of the most prominent globular proteins in blood plasma and serum (35-50 g/L in humans), carries a net negative charge ( $\mathrm{pI}=4.7 ; 66 \mathrm{kDa})$ and functions as an osmotic pressure stabilizer and endo- and exogenous molecule/ion transporter, as well as an antioxidant in blood [29]. Due to its high capacity for binding and transporting molecules and its omnipresence, both in the intra- and extravascular space, serum albumin serves as a relevant model protein to study polyelectrolyte interactions.

Here we present, as a first step, a thermodynamic study of the interaction of synthetic model polyelectrolytes with bovine serum albumin (BSA). Isothermal titration calorimetry (ITC) is used as the tool for providing a precise determination of the binding constant, $K_{\mathrm{b}}$ [30]. Previous work has demonstrated that ITC is the method of choice when $K_{\mathrm{b}}$ has to be obtained with an accuracy high enough to conduct a comprehensive thermodynamic analysis [19,31-33]. Recently, it has been shown that binding constant $K_{\mathrm{b}}$ must be measured as the function of temperature, $T$, and salt concentration, $c_{\mathrm{S}}$, in order to arrive at an understanding of the main driving forces of binding of proteins to polyelectrolytes [34]: (i) First, complex formation between the protein and the polyelectrolyte will release part of the counterions condensed [35-37] to the highly charged polyelectrolyte chain. This counterion release mechanism was established by Record et al. some time ago [1] and has been corroborated in many experimental studies since (cf. the review [12] for further discussion). (ii) The second driving force for binding is the release of water already discussed in the early expositions of the problem [1,38]. A part of the water localized in the hydrate shell of the protein will be released upon binding. Depending on the distribution of the ions between the hydrate and the bulk water, this release will stabilize or destabilize the complex. As shown by Record et al., this effect is intimately related to ion-specific effects embodied in the Hofmeister series [39,40]. 
Both effects have been combined in our recent analysis to yield a closed expression of the free energy of binding, $\Delta G_{b}\left(T, c_{\mathrm{s}}\right)$, as the function of two decisive variables, temperature and salt concentration [34]. Thus, counterion release leads to a term scaling with $\ln c_{\mathrm{S}}$, while the effect of water release scales linearly with $c_{\mathrm{S}}$ (see also the discussion of the Hofmeister effects in [39]). The role of temperature, $T$, requires special consideration. The treatment introduced in [34] works in the vicinity of a maximum of the free energy of binding, $\Delta G_{b}\left(T, c_{s}\right)$, as the function of $T$. Under these conditions, the entropy of binding is smaller than the specific heat, $\Delta c_{p}$, which in turn determines the dependence of $\Delta G_{\mathrm{b}}\left(T, c_{\mathrm{s}}\right)$ on temperature. Hence, we shall first analyse the temperature dependence of the free energy of binding in terms of a novel master curve that allows us to compare the results to other systems $[33,34]$. In a second step, the dependence on $T$ will be analysed together with the dependence on $c_{\mathrm{s}}$. This full analysis [34] of $\Delta G_{\mathrm{b}}\left(T, c_{\mathrm{s}}\right)$ can then be related to the molecular structure of the polyelectrolytes shown in Figure 1.

\section{Materials and Methods}

Materials. Allyl glycidyl ether, tetraoctylammonium bromide, 2,2-dimethoxy-2phenylacetophenone (DMPA) (99\%), 2-(dimethylamino)ethanethiol hydrochloride (95\%), and sodium 3-mercapto-1-propane sulfonate (90\%) were purchased from Sigma-Aldrich (Steinheim, Germany). Cysteamine hydrochloride (97\%) from Fluka and triisobutyl aluminum 1.1 M solution in toluene from Acros Organic were purchased from Fisher Scientific (Schwerte, Germany). The betaine precursor 3-((3-mercaptopropyl)dimethylammonio)propane1-sulfonate was synthesized according to the literature [27]. Allyl glycidyl ether was dried over $\mathrm{CaH}_{2}$ and freshly distilled before use in polymerizations. If not stated otherwise, all materials were used without further purification.

Albumin from bovine serum fraction V (98\%) and sodium chloride ( $\geq 99 \%)$ was received from Carl Roth GmbH+Co. KG (Karlsruhe, Germany). Components of the phosphate buffer sodium phosphate dibasic ( $\geq 99 \%)$, sodium phosphate monobasic $(\geq 99 \%)$ and sodium azide ( $\geq 99 \%$ ) were purchased from Merck Millipore (Darmstadt, Germany). MQ water was prepared via Milli-Q Reference system from Merck with minimum resistivity of $18.2 \mathrm{M} \Omega \cdot \mathrm{cm}$ and with TOC content $<5 \mathrm{ppb}$. For dialysis, pre-wetted regenerated cellulose dialysis tubing with a molecular weight cut-off of $3.5 \mathrm{kDa}$ from SpectrumLabs (Fisher Scientific, Schwerte, Germany) was used.

Synthesis. Poly(allyl glycidyl ether) (PAGE) was obtained via the monomer activated anionic ring-opening polymerization of allyl glycidyl ether in anhydrous toluene according to the literature $[41,42]$. In brief, triisobutyl aluminium (1 eq) and tetraoctylammonium bromide $(0.25 \mathrm{eq})$ were employed as activator and initiator, respectively, while the molecular weight was adjusted via the monomer to initiator concentration ratio. The polymerization was performed at $0{ }^{\circ} \mathrm{C}$ under argon atmosphere for $3 \mathrm{~h}$ at a scale of $40 \mathrm{~g}$ monomer, aiming at a molecular weight of $15 \mathrm{kDA}$. After quenching, the crude polymer was purified via dialysis (MWCO $1 \mathrm{kDa}$ ) in toluene and obtained as a viscous oil in $87.5 \%$ yield after isolation. GPC analysis indicated a molecular weight of $M_{\mathrm{n}}=12.1 \mathrm{kDa}$ and a dispersity of $Ð=1.19$ (Figure S1).

The functional polymers 1-4 were synthesized via UV-initiated thiol-ene postfunctionalization of PAGE in the presence of 2,2-dimethoxy-2-phenylacetophenone (DMPA, $0.2 \mathrm{eq}$ ) with the respective thiols (sodium 3-mercapto-1-propane sulfonate, cysteamine hydrochloride, 2-(dimethylamino)ethanethiol hydrochloride; 3 eq per allyl group) in methanol or-in the case of polymer 2-with 3-((3-mercaptopropyl)dimethylammonio)propane-1sulfonate (3 eq per allyl group) in a mixture of $\mathrm{MeOH}$ : trifluoroethanol: water = 1:1:1 at a concentration of $\sim 3 \mathrm{mg}$ PAGE per mL solvent [43]. The photoreactions were performed for $11 \mathrm{~h}$ under irradiation with a mercury UV-Vis lamp (70 W; LOT-Oriel, Serial No. 266) at scales ranging from $0.1-2 \mathrm{~g}$. For purification, the crude reaction mixture was first dialyzed against $0.5 \mathrm{M} \mathrm{NaCl}$ brine and then excessively against water. After isolation, the product was obtained as a slightly yellow solid in $96,64,28,46 \%$ yield for polymers 1-4, respectively. All NMR spectra can be found in the Supplementary Materials (Figures S2-S11). 
Characterization. Gel permeation chromatography (GPC) of PAGE was performed in tetrahydrofuran at a flow rate of $1 \mathrm{~mL} \mathrm{~min}^{-1}$ at $25^{\circ} \mathrm{C}$, applying polystyrene standards (PSS, Mainz, Germany) on an Agilent 1100 Series instrument (Agilent, Waldbronn, Germany). Three PLgel mixed-C columns (dimensions $7.5 \times 300 \mathrm{~mm}$, particle size $5 \mu \mathrm{m}$; PSS, Mainz, Germany) were used in-line with a refractive index (RI) detector. The molecular weight of the polyelectrolytes was calculated from the weight-average molecular weight of PAGE and the molecular weight of the respective thiol after confirmation of $100 \%$ conversion of all allyl groups via ${ }^{1} \mathrm{H}$ NMR. The precursor PAGE and polymers 1-4 were characterized by ${ }^{1} \mathrm{H}-\mathrm{NMR}$ and ${ }^{13} \mathrm{C}-\mathrm{NMR}$ on a Joel ECX at $400 \mathrm{MHz}$ or a Brucker AVANCE III operating at $700 \mathrm{MHz}$ and $176 \mathrm{MHz}$, respectively. NMR spectra were processed with the software MestReNova 14.1.1; chemical shifts were referenced to the respective deuterated solvent peak $\left(\mathrm{D}_{2} \mathrm{O}\right)$.

Isothermal Titration Calorimetry. ITC experiments were conducted using a Malvern Panalytical (Kassel, Germany) MicroCal VP-ITC instrument, and data was processed with the supplied Microcal module for Origin 7.0 (Additive GmbH, Friedrichsdorf, Germany). All polymer and protein samples were prepared in a phosphate buffer $(9 \mathrm{mM} ; \mathrm{pH} 7.4)$ containing sodium azide ( $2 \mathrm{mM})$ to inhibit microbial growth, which overall resulted in a $23 \mathrm{mM}$ ionic strength. Prior the measurement, all samples were degassed and thermostated for $5 \mathrm{~min}$ at the temperature of the respective experiment. The BSA solution was titrated into the sample cell loaded with $1.43 \mathrm{~mL}$ of the respective polyelectrolyte solution. Polymer and protein concentrations are summarized in Table S2. Titration was accomplished in 58, 78,83 and 116 successive injections of BSA solution ( $5 \mu \mathrm{L}$ each) with a constant stirring rate of $307 \mathrm{rpm}$ and a time interval of 240-360 s between each injection. Measurements with number of injections exceeding 58 were accomplished by two series of injections, and the resulting ITC data were concatenate for analysis as a single file. The heat of dilution was measured, at the conditions of the respective experiment, by titration of BSA solution into the buffer and further subtracted from the heat of adsorption.

Data Analysis: SSIS Model. Data were fit with the single set of independent binding sites (SSIS) model [30]. The SSIS model is based on the Langmuir adsorption theorem and allows one to define the binding constant as:

$$
K_{\mathrm{b}}=\frac{\theta}{(1-\theta)[B S A]}
$$

where $\theta$ is the fraction of the sites occupied by the protein and $[B S A]$ is the concentration of free protein, which is connected with the total concentration of protein $[B S A]_{\text {tot }}$ by equation:

$$
[B S A]_{\mathrm{tot}}=[B S A]+N \theta[P O L]
$$

where $N$ is the number of binding sites and $[P O L]$ is the total polymer concentration. The Langmuir equation assumes an equilibrium between the unoccupied binding sites of the macromolecule, the number of protein molecules in solution, and the occupied binding sites.

Fit parameters are the binding affinity $\left(K_{\mathrm{b}}\right)$, the number of adsorption sites occupied by BSA $\left(N_{\mathrm{b}}=\Theta N\right)$, and the calorimetric enthalpy $\left(\Delta H_{\text {ITC }}\right)$. Figure 2 shows typical fits obtained for the linear cationic polyelectrolyte 4 . All data were corrected for the respective heat of dilution. 

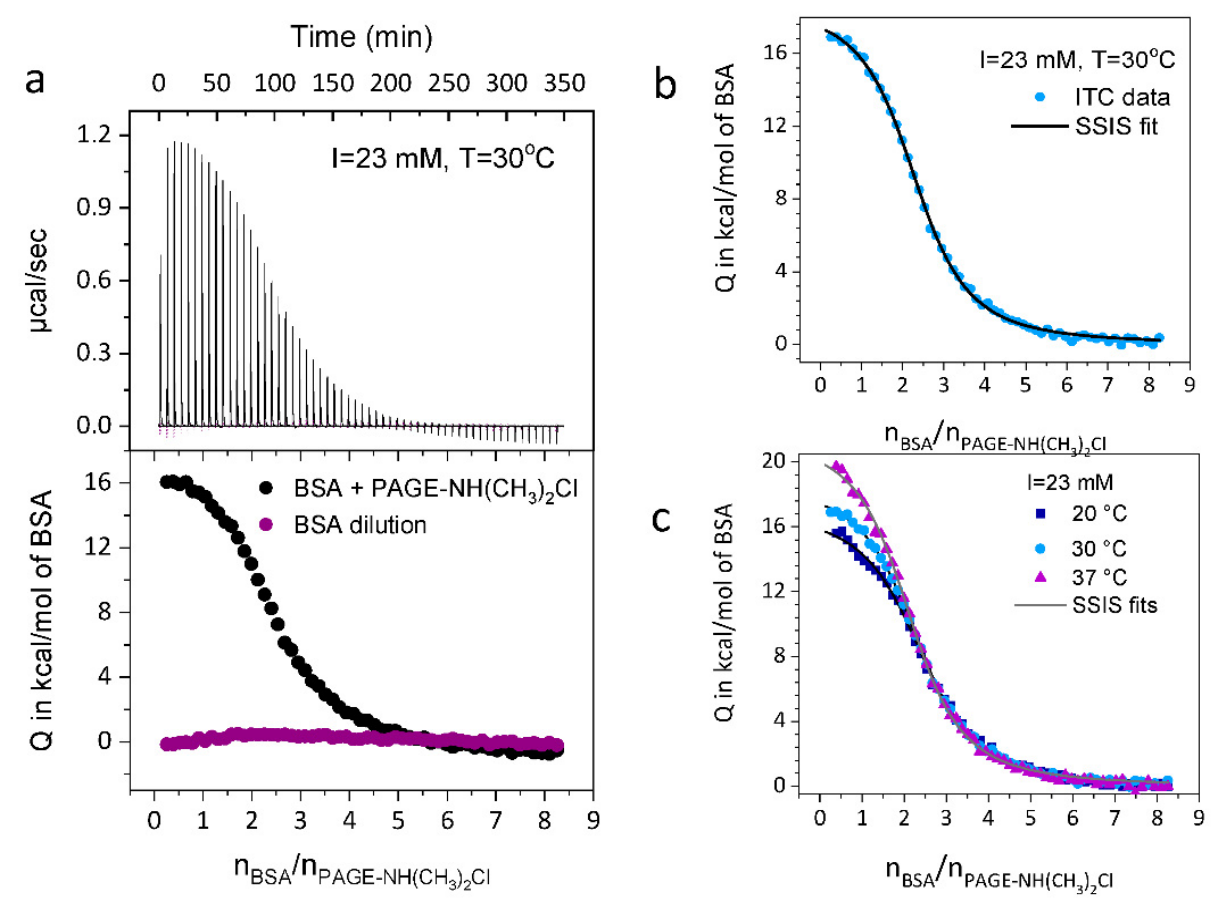

Figure 2. ITC-analysis exemplified for polymer 4. (a) Top panel: the raw data from the titration of BSA to PAGE-NH $\left(\mathrm{CH}_{3}\right)_{2} \mathrm{Cl}$ (black spikes) along with the raw dilution curve of BSA by buffer (purple spikes) at $T=30^{\circ} \mathrm{C}$ and $I=23 \mathrm{mM}$. Lower panel: the integrated heats of each injection. (b) The respective SSIS-fits of curves obtained at $T=30^{\circ} \mathrm{C}$ and (c) $\mathrm{T}=20,30$ and $37^{\circ} \mathrm{C}$. The thermodynamic data derived from these fits are gathered in Table S6.

Theory and Calculations. In the following, a concise derivation and summary of the essential equations for further evaluation of the thermodynamic parameters gained from ITC measurements is given.

Master curve: We first turn to the dependence of the free energy of binding, $\Delta G_{b}\left(T, c_{\mathrm{s}}\right)$, as the function of temperature. The purpose is to develop a master curve for the experimental data independent of any theoretical model. The binding constant, $K_{\mathrm{b}}$, can be measured precisely by isothermal titration calorimetry and is related to $\Delta G_{b}\left(T, c_{\mathrm{s}}\right)$ by:

$$
\Delta G_{\mathrm{b}}=-R T \ln K_{\mathrm{b}}
$$

For most systems in which polyelectrolytes form complexes with proteins, a large specific heat, $\Delta c_{p}$, is found [5]. Thus, $\left|\Delta c_{p}\right| \gg\left|\Delta S_{\mathrm{b}}\right|$ and both $\Delta H_{\mathrm{b}}$ and $\Delta S_{\mathrm{b}}$ exhibit a strong variation with temperature. Therefore, both $\Delta H_{\mathrm{b}}$ and $\Delta S_{\mathrm{b}}$ may become zero in the experimental range of temperatures. In this case, the entropy, $\Delta S_{\mathrm{b}}$, is zero at temperature $T_{\mathrm{s}}$, whereas $\Delta H_{\mathrm{b}}=0$ at temperature $T_{\mathrm{h}}$. As a consequence, the free energy, $\Delta G_{\mathrm{b}}$, has an extremum and stays nearly constant around $T_{\mathrm{s}}$. In the vicinity of these characteristic temperatures, $\Delta H_{\mathrm{b}}$ and $\Delta S_{\mathrm{b}}$ can therefore be expanded to give $[5,6,34,44]$ :

$$
\Delta H_{\mathrm{b}}(T) \cong \Delta H_{\mathrm{b}}\left(T_{\mathrm{s}}\right)+\Delta c_{p}\left(T-T_{\mathrm{s}}\right)
$$

and

$$
\Delta S_{\mathrm{b}}(T) \cong \Delta_{c p} \ln \frac{T}{T_{\mathrm{s}}}
$$

The combination of both expressions leads to the well-known generalized van't Hoff expression [45]:

$$
\Delta G_{\mathrm{b}}(T)=\Delta H_{\mathrm{b}, \mathrm{ref}}-T \Delta S_{\mathrm{b}, \mathrm{ref}}+\Delta c_{p}\left[\left(T-T_{\mathrm{ref}}\right)-T \ln \left(\frac{T}{T_{\mathrm{ref}}}\right)\right]
$$


With the reference temperature, $T_{\text {ref, }}$ given by $T_{\mathrm{S}}$, we obtain:

$$
\Delta G_{\mathrm{b}}(T)=\Delta H_{\mathrm{b}}\left(T_{\mathrm{s}}\right)+\Delta c_{p}\left[\left(T-T_{\mathrm{s}}\right)-T \ln \left(\frac{T}{T_{\mathrm{s}}}\right)\right]
$$

Equations (6) and (7) are exact if the conditions for Equations (4) and (5) are fulfilled. The specific heats, $\Delta c_{p}$, derived from fits of experimental data [31,34], however, are afflicted by a considerable error because this quantity depends critically on the curvature of the plots of $\Delta G_{\mathrm{b}}$ as the function of temperature.

Defining the reduced quantities:

$$
\begin{aligned}
\Delta H_{\mathrm{red}} & =\frac{\Delta H_{\mathrm{b}}}{\Delta c_{p} T_{\mathrm{s}}} \\
\Delta S_{\mathrm{red}} & =\frac{\Delta \mathrm{S}_{\mathrm{b}}}{\Delta c_{p} T_{\mathrm{s}}}
\end{aligned}
$$

we can rewrite Equation (7) as:

$$
\frac{\Delta G_{\mathrm{b}}}{\Delta c_{p} T_{\mathrm{s}}}-\Delta H_{\mathrm{red}}\left(T_{\mathrm{s}}\right)=\frac{T}{T_{\mathrm{s}}}-1-\frac{T}{T_{\mathrm{s}}} \ln \frac{T}{T_{\mathrm{s}}}
$$

with

$$
\Delta G_{\text {red }}=\frac{\Delta G_{\mathrm{b}}}{\Delta c_{p} T_{\mathrm{s}}}
$$

Hence, plots of $\Delta G_{\text {red }}$ as the function of $T / T_{\mathrm{s}}$ should give a master curve for all systems where complex formation was measured in the vicinity of $T_{\mathrm{s}}$. Systems at the same reduced temperature, $T_{\mathrm{r}}=T / T_{\mathrm{s}}$, are in corresponding states and can be compared directly.

With $\Delta T=T-T_{S}$ and series expansion of the logarithmic term in Equation (10a) around $T_{\mathrm{s}}$, we get:

$$
\begin{gathered}
\Delta H_{\text {red }} \approx \Delta H_{\text {red }}\left(T_{\mathrm{s}}\right)+\frac{\Delta T}{T_{\mathrm{s}}} \\
\mathrm{T} \Delta \mathrm{S}_{\mathrm{red}} \approx \frac{\Delta T}{T_{\mathrm{s}}}+\frac{1}{2}\left(\frac{\Delta T}{T_{\mathrm{s}}}\right)^{2} \\
\Delta \mathrm{G}_{\text {red }} \approx \Delta H_{\text {red }}\left(T_{\mathrm{s}}\right)-\frac{1}{2}\left(\frac{\Delta T}{T_{\mathrm{s}}}\right)^{2}
\end{gathered}
$$

Equation (11) shows that $\Delta G_{\text {red }}$ should exhibit a parabolic dependence on $T$ for $T-T_{\mathrm{S}}<20 \mathrm{~K}$. Therefore:

$$
\Delta H_{\text {red }}-\Delta H_{\text {red }}\left(T_{\mathrm{s}}\right) \approx T \Delta S_{\text {red }}-\frac{1}{2}\left(\frac{\Delta T}{T_{\mathrm{s}}}\right)^{2}
$$

Hence, for small $\Delta T / T_{\mathrm{s}}$, the change of enthalpy is entirely compensated by the change of entropy. For temperatures around $T_{\mathrm{s}}$, plots of $\Delta H_{\mathrm{b}}$ versus $T \Delta S_{\mathrm{b}}$ will be linear with slope unity and an intercept, $\Delta H_{\mathrm{b}}\left(T_{\mathrm{s}}\right)$. For larger $\Delta T$, the compensation of $\Delta H_{\mathrm{b}}$ and $\Delta S_{\mathrm{b}}$ is no longer complete.

Theory of complex formation: The foregoing analysis of the data is purely phenomenological and can only serve as check of internal consistency of the data. Recently, we have developed a theoretical model which allows us the analysis of $\Delta G_{\mathrm{b}}$ on salt concentration, $c_{S}$, and temperature by a single expression [34]. Here, we only summarize the main equations necessary for the evaluation of data. Earlier work has clearly demonstrated that water release leads to an additional term in $\Delta G_{\mathrm{b}}$, scaling linearly with $c_{\mathrm{S}}[1,39]$. Hence [34]:

$$
\Delta G_{\mathrm{b}}\left(T, c_{\mathrm{s}}\right)=\mathrm{RT} \Delta n_{\mathrm{ci}} \ln c_{\mathrm{s}}-\mathrm{RT} 0.036 c_{\mathrm{s}} \Delta w+\Delta G_{\mathrm{res}}
$$

where $\Delta w$ describes the dependence of the free energy of binding on water release and $\Delta G_{\text {res }}$ is a constant to be specified below [46]. Thus, $T$ and $c_{\mathrm{S}}$ are the decisive variables that 
determine $\Delta G_{\mathrm{b}}\left(T, c_{\mathrm{s}}\right)$. Combination with Equations (4) and (5) above then leads to a closed expression for $\Delta G_{\mathrm{b}}\left(T, c_{\mathrm{s}}\right)[34]$ :

$$
\Delta G_{\mathrm{b}}\left(T, c_{\mathrm{s}}\right)=R T \Delta n_{\mathrm{ci}} l n c_{\mathrm{s}}+\Delta H_{0}-\mathrm{T} \Delta S_{0}+c_{\mathrm{s}} \frac{\mathrm{d} \Delta c_{p}}{\mathrm{~d} c_{\mathrm{s}}}\left[T-T_{0}-T \ln \left(\frac{T}{T_{0}}\right)\right]
$$

Here, the first term describes the contribution of counterion release to the free energy of binding. The quantity, $\Delta n_{\mathrm{ci}}$, is the number of released counterions upon complex formation. The last term describes the effect of water release on $\Delta G_{b}\left(T, c_{s}\right)$ in terms of a new characteristic temperature, $T_{0}$, whereas $\Delta H_{0}$ and $T \Delta S_{0}$ give the additional enthalpic and entropic contributions at $T=T_{0}$. The respective enthalpy, $\Delta H_{\mathrm{b}}$, and entropy, $\Delta S_{\mathrm{b}}$, of binding read [34]:

$$
\Delta H_{\mathrm{b}}\left(c_{\mathrm{s}}, T\right)=\Delta H_{0}+\frac{\mathrm{d} \Delta c_{p}}{\mathrm{~d} c_{\mathrm{s}}} c_{\mathrm{s}}\left(T-T_{0}\right)
$$

and

$$
\Delta S_{\mathrm{b}}\left(c_{\mathrm{s}}, T\right)=\Delta S_{0}-\Delta n_{\mathrm{ci}} R \cdot \ln \left(c_{\mathrm{s}}\right)+\frac{\mathrm{d} \Delta c_{p}}{\mathrm{~d} c_{\mathrm{s}}} c_{\mathrm{s}} \ln \left(\frac{T}{T_{0}}\right)
$$

The quantity, $\Delta w$, follows as [34]

$$
\Delta w=\frac{\frac{\mathrm{d} \Delta c_{p}}{\mathrm{~d} c_{\mathrm{s}}}}{0.036 R}\left(\ln \frac{T}{T_{0}}+\frac{T_{0}}{T}-1\right)
$$

showing that the effect of water release has an extremum at $T=T_{0}$. For a positive coefficient, $\frac{\mathrm{d} \Delta c_{p}}{\mathrm{~d} c_{\mathrm{s}}}$, the effect of water release will hence increase the magnitude of $\Delta G_{\mathrm{b}}$ and enhance the strength of binding. The parameter $\Delta w$ has been repeatedly determined from fits of Equation (13) to experimental data and interpreted as the number of released water molecules during complex formation $[7,9,10]$. Equation (17) shows, however, that this parameter depends sensitively on temperature and vanishes at $T=T_{0}$. Hence, $\Delta w$ defies direct interpretation and must be viewed as a measure for the contribution of water release to the free energy of binding (see the discussion in [34] and further below).

Finally, the residual free energy, $\Delta G_{\text {res, }}$, is given by [34]:

$$
\Delta G_{\text {res }}=\Delta H_{0}-T_{0} \Delta S_{0}
$$

This contains all contributions to the free energy of binding such as, e.g., hydrogen bonding after removal of the parts related to counterion release and water release. It may also describe possible contributions to $\Delta G_{\mathrm{b}}$ that are due to, e.g., conformational changes upon complex formation or salt bridges in the complex [46]. In total, Equation (14) provides a means to split up to the measured free energy of binding into three parts, namely: the effect of counterion release embodied in the logarithmic term; the effect of water release (cf. Equation (17)); and a term that covers all other effects. Thus, it allows us to quantify the role of water during complex formation.

\section{Results and Discussion}

The polyelectrolytes 1-4 were synthesized by post-modification of PAGE $\left(M_{\mathrm{n}}=12.1 \mathrm{kDa}\right.$, $Ð=1.19)$ via thiol-ene reactions and purified by consecutive dialysis against salt solution and then pure water. ${ }^{1} \mathrm{H}$ NMR and ${ }^{13} \mathrm{C}$ NMR analysis indicated full conversion of the pendent allyl groups with the respective thiols. The opted post-modification strategy allowed the attainment of polyelectrolytes (Table S1) comprising the same number of around 100 repeating units (r.u.) for comparative binding studies with biomolecules. The lyophilized polyelectrolytes were dissolved in phosphate buffer $(9 \mathrm{mM}$; $\mathrm{pH} 7.4)$ to achieve the requisite concentrations and used for the ITC experiments after ionic strength adjustment.

Analysis by ITC: The present analysis relies on precise data of the free energy of binding as the function of the two decisive variables temperature, $T$, and salt concentration, $c_{\mathrm{s}}$. In order to obtain the necessary accuracy, the subtraction of the heat of dilution must be 
done very carefully. We found that the anionic polysulfonate $\mathbf{1}$ binds weakly to BSA if the ionic strength is low (see Figures S12 and S13 in the Supplementary Materials), whereas the charge-neutral sulfonate-based polyzwitterion 2 does not allow evaluation via ITC under the applied conditions, suggesting the absence of any binding interaction with BSA (see Figure S14 in the Supplementary Materials). In contrast, a strong binding of BSA to the cationic polyamines 3 and 4 with pendant primary amine or tertiary dimethyl amine functionalities was observed. Figure 2 displays a typical example of the analysis of the binding of BSA to polymer 4. All ITC-runs of polymers 3 and $\mathbf{4}$ are shown in Figures S15-S18, respectively, while Tables S4-S7 gather the resulting thermodynamic data.

The fact that the anionic polysulfonate $\mathbf{1}$ binds only weakly to BSA at the ionic strength employed here comes as no surprise. In a previous investigation, we studied the binding of poly(acrylic acid) to HSA [19]. Here we found that binding occurred only at the lowest salt concentration of $20 \mathrm{mM}$, whereas a higher concentration of $50 \mathrm{mM}$ already led to a very weak binding which was hardly measurable. The reason for this finding is located in the electrostatic repulsion of the polyelectrolyte and the like-charged BSA [12]. The thermodynamic analysis (Table S3) revealed an inconsistent number, $N=0.2-0.7$, of bound polymer 1 chains per BSA within the applied range of temperature and salt concentration which, together with the low binding constant, $K_{b}$, did not allow further detailed analysis of this data set. In the case of the apparently charge-neutral polymer $\mathbf{2}$, we see the well-known stealth effect of zwitterionic polyelectrolytes, which do not interact strongly with proteins $[47,48]$. Due to the firm hydration of zwitterions, they hardly adsorb to biomolecules in solution or at biointerfaces [49]. Thus, flexible polyzwitterions, which exhibit limited electrostatic self-association capacity, combine an entropic with an enthalpic penalty derived from reduced chain flexibility and forced unfavourable dehydration upon complex formation with, e.g., proteins [50]. Hence, in the following, we shall discuss only the thermodynamic data obtained for the cationic polymers 3 and 4 .

The analysis by ITC leads to the binding constant, $K_{\mathrm{b}}$, the number of bound BSAmolecules per polymer chain, $N$, and the heat, $\Delta H_{\text {ITC }}$. The binding constant $K_{\mathrm{b}}$ can be converted into the free energy of binding via Equation (3) and provides the basis for the entire thermodynamic analysis. For polymer 3, we find that $N$ varies between 2.0 and 2.4, whereas $N$ is 2.3-2.5 for polymer 4 (see Tables S4-S7). The slight variance of $N$ with temperature and salt concentration may be due to the polydispersity of the polyelectrolyte chains.

Figure 3 delineates the first step of the analysis of $\Delta G_{\mathrm{b}}\left(T, c_{\mathrm{s}}\right)$ with respect to temperature, T. Here, fits of Equation (7) to experimental data are shown. Excellent fits can be achieved for both polymers 3 and 4 . However, the resulting specific heat, $\Delta c_{p}$, is afflicted by an error of about $50 \%$. The resulting parameters are gathered in Table 1 . The maximal values of the free energy of binding, which equal $\Delta H_{\mathrm{b}}\left(T_{\mathrm{s}}\right)$, agree for both systems 3 and 4 , which may be traced back to their structural similarity on the molecular level. The other parameters, namely $\Delta c_{p}$ and the temperature $T_{\mathrm{s}}$, at which the maximum value of $\Delta G_{\mathrm{b}}$ is reached defy direct interpretation. However, the entire comparison suggests that both systems are directly comparable and interact with BSA in a similar manner. Moreover, this analysis provides the enthalpy and the entropy of reaction $\Delta H_{\mathrm{b}}$ and $\Delta S_{\mathrm{b}}$, which can later be compared to Equations (15) and (16), respectively.

Table 1. Thermodynamic parameters obtained from fits of Equations (7) and (14) with an estimate of their error margins.

\begin{tabular}{|c|c|c|c|c|c|c|c|c|}
\hline Polymer & 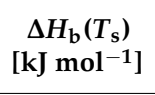 & 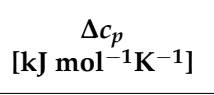 & $\begin{array}{c}T_{\mathrm{s}} \\
{[\mathrm{K}]}\end{array}$ & $\begin{array}{c}T_{0} \\
{[\mathrm{~K}]}\end{array}$ & $\Delta n_{\mathrm{ci}}$ & $\begin{array}{c}\frac{d c_{p}}{d c_{s}} \\
{\left[\mathrm{~kJ} \mathrm{~mol}^{-1} \mathbf{K}^{-1} \mathbf{M}^{-1}\right]}\end{array}$ & $\begin{array}{c}\Delta H_{0} \\
{\left[\mathrm{~kJ} \mathrm{~mol}^{-1}\right]}\end{array}$ & $\begin{array}{c}\Delta S_{0} \\
{\left[\mathrm{~kJ} \mathrm{~K}^{-1} \mathrm{~mol}^{-1}\right]}\end{array}$ \\
\hline 3 & $-30 \pm 5$ & $2.2 \pm 0.5$ & $271 \pm 4$ & $285 \pm 3$ & $2.76 \pm 0.03$ & $82 \pm 8$ & $6.4 \pm 0.5$ & $0.044 \pm 0.004$ \\
\hline 4 & $-30 \pm 5$ & $0.9 \pm 0.5$ & $263 \pm 4$ & $285 \pm 3$ & $2.27 \pm 0.03$ & $14 \pm 2$ & $-1.7 \pm 0.2$ & $0.031 \pm 0.003$ \\
\hline
\end{tabular}

$\Delta H_{\mathrm{b}}\left(T_{\mathrm{s}}\right)$ : enthalpy of binding at $T=T_{\mathrm{s}}$ (Equation (7)); $\Delta c_{p}$ : specific heat of binding determined from fits of Equation (7) to experimental data; $T_{\mathrm{s}}$ : temperature where the entropy of binding vanishes; $T_{0}$ : characteristic temperature defined through Equation (14); $\Delta n_{\mathrm{ci}}:$ net number of released counterions (Equation (14)); $\mathrm{d} \Delta c_{p} / \mathrm{d} c_{s}$ : coefficient defining water release (Equation (14)); $\Delta H_{0}, \Delta S_{0}$ : residual enthalpy and entropy of binding, respectively, as defined through Equation (14). 

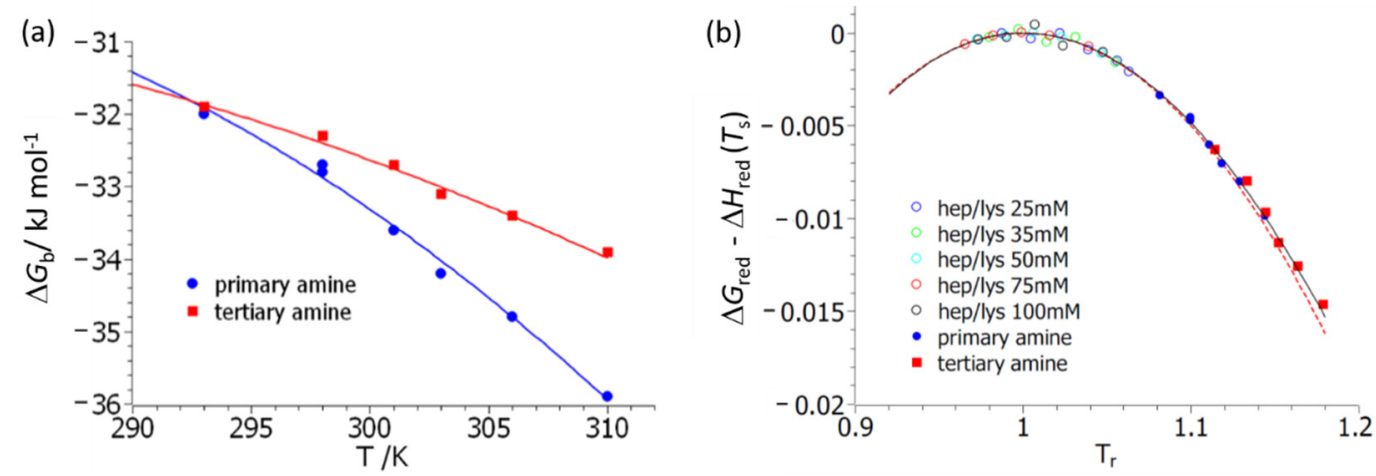

Figure 3. Analysis of the free energy, $\Delta G_{b}$, of complex formation between BSA and polymers 3 (primary amine) and 4 (tertiary amine), respectively, according to Equations (7) and (10a). (a) Fits of Equation (7) to experimental data. The parameters obtained from this fit are gathered in Table 1. (b) Analysis of the data in terms of the master curve Equation (10a). The reduced free energy of binding, $\Delta G_{\text {red }}$, is plotted against the reduced temperature, $T_{\mathrm{r}}=T / T_{\mathrm{s}}$. The solid line denotes the exact results, whereas the dashed line displays the series expansion according to Equation (11). The hollow points refer to the data obtained for the system heparin/lysozyme studied in [33].

$\Delta H_{\mathrm{b}}\left(T_{\mathrm{s}}\right)$ : enthalpy of binding at $T=T_{\mathrm{s}}$ (Equation (7)); $\Delta c_{p}$ : specific heat of binding determined from fits of Equation (7) to experimental data; $T_{\mathrm{s}}$ : temperature where the entropy of binding vanishes; $T_{0}$ : characteristic temperature defined through Equation (14); $\Delta n_{\mathrm{ci}}$ : net number of released counterions (Equation (14)); $\mathrm{d} \Delta c_{p} / \mathrm{d} c_{\mathrm{S}}$ : coefficient defining water release (Equation (14)); $\Delta H_{0}, \Delta S_{0}$ : residual enthalpy and entropy of binding, respectively, as defined through Equation (14).

Figure $3 b$ displays the same data but now plotted according to master curve Equation (10a). The solid line gives the exact expression of Equation (10a), whereas the dashed line displays the approximation of Equation (11). The hollow points show the respective thermodynamic data obtained for the binding of lysozyme to heparin studied and reported previously [33]. The calculation of the reduced free energy involves small differences of large numbers, and the plot in Figure $3 b$ shows that the data have sufficient accuracy for a meaningful comparison. Figure $3 b$ demonstrates that all data are described by the master curve Equation (10a). This in turn assures that Equations (4) and (5) present valid approximations, and further evaluation by Equation (14) is possible.

The data gathered in Table 1 demonstrate that $\Delta c_{p}$ is of appreciable magnitude, which in turn must lead to a strong compensation of entropy by enthalpy $[5,6,34,44]$. Equation (12) shows that this compensation must be total if $\Delta T$ is sufficiently small. This in turn is fulfilled if the reduced temperature, $T_{\mathrm{r}}$, is close to unity.

We now turn to the evaluation of the data according to Equation (14). Two variables determine the free energy of binding, $\Delta G_{\mathrm{b}}$ : the temperature, $T$, and the salt concentration, $c_{\mathrm{s}}$. The experimental $\Delta G_{\mathrm{b}}\left(T, c_{\mathrm{s}}\right)$ is fitted by Equation (14) by the MathLab routine $c f t o o l$ to yield the parameters gathered in Table 1. As already discussed in [34], the parameters $\Delta H_{0}$ and $\Delta S_{0}$ can be determined securely because an entire set of data depending of $T$ and $c_{\mathrm{s}}$ is fitted. The parameter $\mathrm{d} \Delta c_{p} / \mathrm{d} c_{\mathrm{s}}$ depends very much on the curvature of $\Delta G_{\mathrm{b}}$ as the function of temperature and is therefore afflicted by a larger error; $\Delta n_{\mathrm{ci}}$, on the other hand, can be determined very precisely [34]. Figure 4 displays the resulting fits, both as the function of $T$ (Figure $4 \mathrm{a}$ ) and of salt concentration, $c_{\mathrm{S}}$ (Figure $4 \mathrm{~b}$ ). Here it should be kept in mind that this rendition serves only for better visibility; all data are described by a single set of parameters. The interpretation of the experimental data in terms of Equation (14) differs from the fit according to Equation (10a) in a central point; Equation (14) contains the explicit dependence of $\Delta G_{\mathrm{b}}$ on counterion release. Its removal therefore allows us to discuss the other factors leading to complex formation in a quantitative way. 
(a)

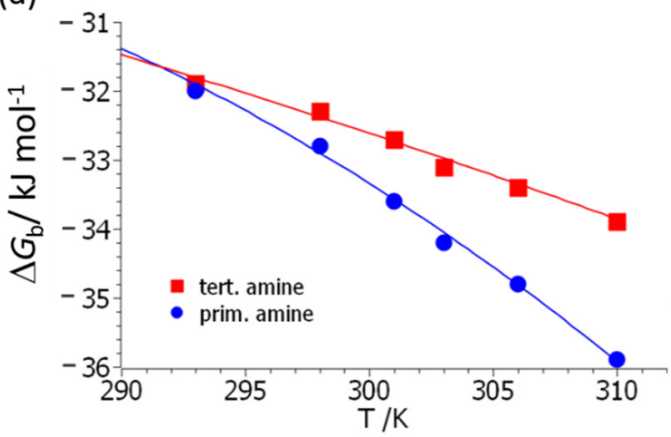

(b)

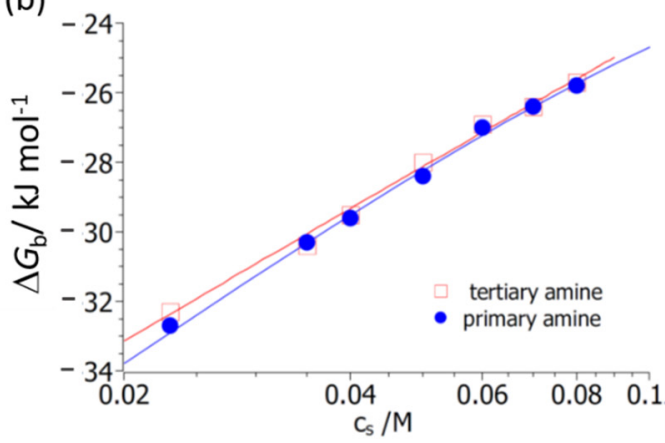

Figure 4. Comparison of theory and experiment. (a) The free energy of binding, $\Delta G_{b}$, is plotted against the temperature for polymers 3 (primary amine) and 4 (tertiary dimethyl amine). The salt concentration was fixed at $c_{\mathrm{S}}=23 \mathrm{mM}$ for all data. (b) The free energy of binding, $\Delta G_{\mathrm{b}}$, is plotted against the salt concentration, $c_{\mathrm{S}}$, at a fixed temperature of $298 \mathrm{~K}$ for polymers 3 (primary amine) and 4 (tertiary dimethyl amine). The solid lines mark the fit by Equation (14) in both figures.

Figure 4 demonstrates that a quantitative fit of all data can be achieved. The parameter $\Delta n_{\mathrm{ci}}$ is slightly higher for polymer 3 compared to polymer 4 . It should be kept in mind that this quantity presents the net number of released counter- and co-ions. In all previous investigations, the parameter $\Delta n_{\mathrm{ci}}$ was deduced from the slope of plots, as shown in Figure $4 \mathrm{~b}$. For both polymers 3 and 4 , these plots are linear within the limits of error. However, close inspection of Equation (14) reveals that this can only be the case if the data have been measured at temperatures close to $T_{0}$ [34]. Figure $4 \mathrm{~b}$ therefore shows small deviations from linearity, and the value of the parameter $\Delta n_{\mathrm{ci}}$ obtained directly from the slope of the plot may be slightly different as compared to the one derived from Equation (14). The exact structure of the complex between BSA and polymers 3 and 4 cannot be deduced from the present set of data. In our previous analysis of the binding of HSA to poly(acrylic acid) [19], we found $\Delta n_{\mathrm{ci}} \cong 3$, which is slightly higher than the values (2.8 for polymer 3 and 2.3 for polymer 4 ) derived here (Table 1 ).

As mentioned above, the fit according to Equation (14) allows us to split off the effect of counterion release on the free energy of binding, $\Delta G_{\mathrm{b}}$. Thus, all other parameters refer to the remaining factors leading to complex formation. We first discuss the parameters that refer to the relation of $\Delta G_{\mathrm{b}}\left(T, c_{\mathrm{s}}\right)$ to the release of water molecules during complex formation, namely, the last term in Equation (14). It is interesting to note that both systems have the same characteristic temperature, $T_{0}$. This finding may be traced back to a similar binding strength between $\mathrm{H}_{2} \mathrm{O}$ and the polymer chains. The main difference resides in the parameter $\mathrm{d} \Delta c_{p} / \mathrm{d} c_{\mathrm{s}}$, which measures the gain of free energy with increasing salt concentration for a given temperature difference, $T-T_{0}$. For both polymers, this coefficient is positive, and water release will therefore increase the free energy of binding. In the case of polymer 3 , this increase is larger by a factor of nearly 6 as compared to polymer 4 . Hence, this factor reflects the fact that the magnitude of $\Delta G_{b}$ is increasing much more for polymer 3 as compared to polymer 4 when increasing the temperature from $T_{0}$ to $310 \mathrm{~K}$ (see Figure 4a). In other words, the effect of water release on $\Delta G_{\mathrm{b}}$ with raising temperature is increasing much more for polymer $\mathbf{3}$ than for polymer 4.

As outlined previously [34], the quantity, $\Delta w$ (see Equation (17)), can be interpreted in terms of the solute partitioning model (SPM) by Record et al. [39,40]. The SPM describes the interaction of the ions with the protein in aqueous solution by a combination of an ion-specific interaction and the non-specific lowering of the water activity by the salt ions. The former contribution is directly related to the Hofmeister series [40]. During complex formation, $\Delta B_{\mathrm{H} 2 \mathrm{O}}$ water molecules will be released. The relation of the SPM to the present model is given by [34]:

$$
\Delta w=\frac{1}{2}\left(K_{\mathrm{p},+}+K_{\mathrm{p},-}-2\right) \Delta B_{\mathrm{H} 2 \mathrm{O}}
$$


where partition coefficient $K_{\mathrm{p},+}=\left(m_{+}^{\text {loc }} / m_{+}^{\text {bulk }}\right)$ describes the distribution of the cations between the hydrate and the bulk water. Thus, $m_{+}^{\text {loc }}$ is the molality of the cations in the hydrated shell, whereas $m_{+}^{\text {bulk }}$ is the respective quantity in bulk. The anions are distributed in the same way characterized by the partition coefficient, $K_{\mathrm{p},-}$. Analogously, the partition coefficient, $K_{\mathrm{p},-}$, refers to the partition of the anions between the hydrate shell and the bulk water. For salt ions in the middle of the Hofmeister series, these partition coefficients are approximately unity, and the contribution of water release to $\Delta G_{\mathrm{b}}$ is small. At $T=T_{0}$, $\Delta w$ vanishes and the present model predicts a parabolic dependence on $T-T_{0}$ according to Equation (17). The coefficient $\mathrm{d} \Delta c_{p} / \mathrm{d} c_{\mathrm{s}}$ is a quantitative measure for the effect of water release at a certain $T-T_{0}$.

The data gathered in Table 1 refer to two different polyelectrolytes interacting with the same protein, BSA. Hence, the differences seen for polymer 4 compared to polymer 3 must be traced back to a differential local interaction of both polymers with BSA. Because the effects seen here cannot be solely attributed to the hydration of the protein, it necessarily implies that it is the hydration of the polymers which causes the observed difference. This is reasonable as dimethyl amino groups are generally less hydrated compared to primary amino groups due to the replacement of two hydrogen bond donating substituents on the nitrogen with methyl groups. Thus, the resulting parameters gathered in Table 1 can be explained as follows: First of all, the number of released counterions, $\Delta n_{\mathrm{ci}}$, is slightly but significantly higher for polymer 3 . This may be due to the shorter distance between the cationic charge and the surface of the protein in the case of polymer 3 , whereas there may be a steric hindrance due to the methyl groups in the case of polymer 4. Concomitantly, a closer interaction between the primary amine group with the surface of BSA is followed by a stronger release of water, as measured by the coefficient $\mathrm{d} \Delta c_{p} / \mathrm{d} c_{\mathrm{s}}$. As mentioned above, the quantities $\Delta H_{0}$ and $\Delta S_{0}$ refer to the residual free energy after splitting off both the contributions of counterion and water release. The data gathered in Table 1 show that $\Delta H_{0}$ is small for both polymers 3 and 4 , and the residual free energy is mainly entropic.

The discussion of the parameters deriving from the fits to Equation (14) allow us to discern between the main contributions to the free energy of binding, namely counterion release and hydration and their relation to ionic strength; counterion release is dominant at low ionic strength and diminishes logarithmically with increasing salt concentration. The contribution originating from hydration, however, scales linearly with salt concentration and therefore increases strongly with increasing salinity of the solution. At physiological ionic strength, hydration may therefore become the leading term in $\Delta G_{b}$ if the temperature differs significantly from $T_{0}$. The parameters gathered in Table 1 therefore allow us to extrapolate $\Delta G_{\mathrm{b}}$ to conditions where ITC-measurements have become insecure.

Finally, we discuss the marked enthalpy-entropy compensation as embodied in Equation (14) [34]. First, it should be noted that the heat, $\Delta H_{\text {ITC }}$, measured directly in the ITC-experiment is not necessarily the heat of reaction, $\Delta H_{\mathrm{b}}$. This fact has already been observed in early work [45] and can be explained by linked equilibria (see, e.g., the discussion of this point in [34]): If complex formation is connected to the uptake or release of protons, the equilibration of the $\mathrm{pH}$ by the buffer will lead to an additional heat effect caused by the uptake/release of protons by the buffer. This heat is not related to complex formation but is also contained in $\Delta H_{\text {ITC }}$. Experiments with buffers differing in the heat of protonation have shown this clearly, and the true heat of reaction can only be obtained by extrapolation of $\Delta H_{\text {ITC }}$ to a vanishing heat of protonation of the buffer [34]. We therefore use only the binding enthalpies, $\Delta H_{\mathrm{b}}$, derived from fits of Equation (7) to the experimental data.

The strong enthalpy-entropy compensation can now be discussed in more detail using Equations (15) and (16). Figure 5 displays a comparison between the enthalpy and entropy obtained from the fits of the generalized van't Hoff equation (7) to the experimental data obtained for polymer 3 (primary amine); the respective comparison for polymer 4 is shown in Figure S19 of the Supplementary Materials. The dashed lines in Figure 5a display these data, whereas the full lines show the results of Equations (15) and (16) using the parameters gathered in Table 1. Full agreement within the prescribed limits of error is seen. 

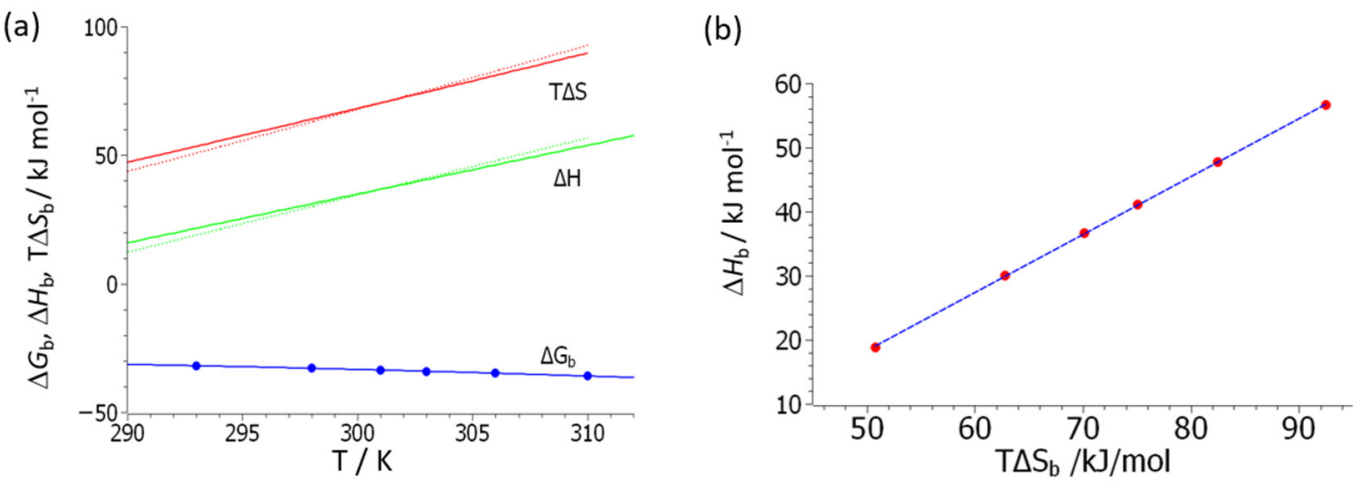

Figure 5. Enthalpy-entropy compensation for the data obtained from polymer 3 (primary amine). (a) The blue circles denote the measured free energy of binding, whereas the blue solid line gives the respective fit by Equation (14). The solid green and red lines give the enthalpy Equation (15) and the entropy multiplied by $T$ as obtained from Equation (16), respectively. The respective dashed lines denote the enthalpy Equation (4) and the entropy Equation (5) deriving from the fit of Equation (7) to the experimental data. (b) The enthalpy, $\Delta H_{\mathrm{b}}$ (cf. Equation (4)), obtained from the fit of the experimental data according to Equation (7) is plotted against $T \Delta S_{\mathrm{b}}$ (Equation (5)). The slope of the dashed line is 0.9 , indicating an incomplete compensation of enthalpy by entropy. See text for further explanation.

The compensation of enthalpy by entropy is not complete, as can be seen from Figure $5 \mathrm{~b}$ and Figure S19b. Here we plot the enthalpy, $\Delta H_{\mathrm{b}}$, calculated by Equation (4) against $T \Delta S_{\mathrm{b}}$ (Equation (5)), where the respective constants $\Delta H_{\mathrm{b}}\left(T_{\mathrm{s}}\right)$ and $\Delta c_{p}$ have been determined by a fit of Equation (7) to the experimental data obtained on polymer 3 . The slope of the dashed line in Figure $5 b$ is 0.9 , which indicates that the enthalpy of binding is not entirely compensated by entropy. This finding is due to the fact that the data for polymer 3 have been taken at a rather high reduced temperature of $T_{r}>1.1$. Therefore, the term scaling with $\Delta T^{2}$ in Equation (12) is no longer negligible and the enthalpy-entropy compensation no longer complete, as has been found for the system heparin/lysozyme (see the open circles in Figure $3 \mathrm{~b}$ and the discussion in [33]). It should be noted, however, that the generalized van't Hoff fit Equation (7) is afflicted by a considerable error and a fit according to Equation (14) is by far better and more stable.

\section{Conclusions}

We have presented a thermodynamic analysis of the interaction of linear polyelectrolytes with bovine serum albumin (BSA). All polyelectrolytes are derived from the same main chain by polymer-analogous reaction (see Figure 1) and only differ regarding the chemical group presenting the charge and the sign of the charge. We found the anionic polymer $\mathbf{1}$ to only weakly interact while the zwitterionic polymer $\mathbf{2}$ does not interact at all with BSA under the applied conditions. A strong binding, however, was found for the cationic polymers 3 and 4 , which could be analysed in detail by ITC. The analysis was performed using Equation (14), which describes the free energy of binding $\Delta G_{\mathrm{b}}$ as the function of temperature, $T$, and salt concentration, $c_{\mathrm{s}}$. The underlying model splits $\Delta G_{\mathrm{b}}$ into a term related to counterion release and a term related to water release [34]. The main result of this analysis is the observation that the release of water, as expressed in the coefficient $\mathrm{d} \Delta c_{p} / \mathrm{d} c_{s}$, is more important for polymer 3 , which bears primary amino groups (cf. Table 1 ). We explain this finding by a closer contact of this polymer with BSA in the complex when compared to polymer 4 comprising bulkier tertiary amino groups. In addition, the latent hydrophobicity of the tertiary dimethyl amine groups in polymer 4 compared to the more hydrophilic primary amines generally results in a weaker hydration which may contribute to the overserved lower degree of released water upon complex formation between BSA and polymer 4 . The entire discussion of the data in terms of Equation (14) demonstrates that the binding strength, $\Delta G_{\mathrm{b}}$, can be dissected quantitatively into different contributions 
that depend on temperature and salt concentration. In this way, a full understanding of complex formation between polyelectrolytes and proteins can be achieved.

Future studies will focus on the investigation of synthetic polycations with additional biocompatibilising pendant groups such as charge-neutral zwitterions or oligoethylene glycols.

Supplementary Materials: The following are available online at https://www.mdpi.com/article/ 10.3390/biom11091377/s1. Polyelectrolyte characterization (GPC and NMR data) as well as ITC measurement conditions with raw data and basic analysis can be found in the Supplementary Information. Figure S1: GPC profile of the precursor polymer PAGE in THF as the eluent applying PS-standards, Figure S2: ${ }^{1} \mathrm{H}-\mathrm{NMR}$ of PAGE $\left(\mathrm{CDCl}_{3}, 400 \mathrm{MHz}\right)$, Figure S3: ${ }^{13} \mathrm{C}-\mathrm{NMR}$ of PAGE $\left(\mathrm{CDCl}_{3}, 175 \mathrm{MHz}\right)$, Figure S4: ${ }^{1} \mathrm{H}-\mathrm{NMR}\left(400 \mathrm{MHz}, \mathrm{D}_{2} \mathrm{O}\right)$ of polymer 1 (PAGE-SO $\left.3 \mathrm{Na}\right)$, Figure S5: ${ }^{13} \mathrm{C}-\mathrm{NMR}\left(176 \mathrm{MHz}, \mathrm{D}_{2} \mathrm{O}\right)$ of polymer 1 (PAGE-SO $\left.{ }_{3} \mathrm{Na}\right)$, Figure $\mathrm{S6}:{ }^{1} \mathrm{H}-\mathrm{NMR}\left(400 \mathrm{MHz}, \mathrm{D}_{2} \mathrm{O}\right)$ of polymer 2 (PAGE-N $\left.\left(\mathrm{CH}_{3}\right)_{2}-\left(\mathrm{CH}_{2}\right)_{3}-\mathrm{SO}_{3}{ }^{-}\right)$, Figure S7: ${ }^{13} \mathrm{C}-\mathrm{NMR}\left(176 \mathrm{MHz}, \mathrm{D}_{2} \mathrm{O}\right)$ of polymer 2 (PAGE-N $\left.{ }^{+}\left(\mathrm{CH}_{3}\right)_{2}-\left(\mathrm{CH}_{2}\right)_{3}-\mathrm{SO}_{3}{ }^{-}\right)$, Figure S8: ${ }^{1} \mathrm{H}-\mathrm{NMR}\left(400 \mathrm{MHz}, \mathrm{D}_{2} \mathrm{O}\right)$ of polymer 3 (PAGE- $\mathrm{NH}_{3} \mathrm{Cl}$ ), Figure S9: ${ }^{13} \mathrm{C}-\mathrm{NMR}\left(176 \mathrm{MHz}, \mathrm{D}_{2} \mathrm{O}\right)$ of polymer 3 (PAGE-NH $\left.\mathrm{H}_{3} \mathrm{Cl}\right)$, Figure S10: ${ }^{1} \mathrm{H}-\mathrm{NMR}(400 \mathrm{MHz}$, $\mathrm{D}_{2} \mathrm{O}$ ) of polymer 4 (PAGE-NHMe $2 \mathrm{Cl}$ ), Figure $\mathrm{S11}{ }^{13} \mathrm{C}-\mathrm{NMR}\left(176 \mathrm{MHz}, \mathrm{D}_{2} \mathrm{O}\right.$ ) of polymer 4 (PAGE$\mathrm{NHMe}_{2} \mathrm{Cl}$ ), Table S1: Overview of molecular weight of functional polymers 1-4, Table S2: Summary of used concentrations and measurement conditions in ITC experiments, Figure S12: ITC data of the adsorption of BSA onto polymer $\mathbf{1}$ (PAGE-SO $\mathrm{P}_{3} \mathrm{Na}$ ) (black curves) with the corresponding heats of dilution of BSA (blue curves) at $\mathrm{pH}=7.4, \mathrm{I}=23 \mathrm{mM}$ and (a) $\mathrm{T}=25^{\circ} \mathrm{C}$, (b) $\mathrm{T}=30^{\circ} \mathrm{C}$, (c) $\mathrm{T}=37^{\circ} \mathrm{C}$. (d) Binding isotherms corrected for the heat of dilution at $T=25,30,37^{\circ} \mathrm{C}$ and $23 \mathrm{mM}$, Figure S13: ITC data of adsorption of BSA onto polymer $\mathbf{1}$ (PAGE-SO ${ }_{3} \mathrm{Na}$ ) (black curves) with the corresponding heats of dilution of BSA (blue curves) at $\mathrm{pH}=7.4, T=25^{\circ} \mathrm{C}$ and (a) $I=23 \mathrm{mM}$, (b) $I=35 \mathrm{mM}$, (c) $I=40 \mathrm{mM}$, (d) $I=50 \mathrm{mM}$, (e) $I=80 \mathrm{mM}$. (d) Binding isotherms corrected for the heat of dilution at $T=25^{\circ} \mathrm{C}$ for all ionic strengths, Table S3: Thermodynamic parameters of the binding between BSA $(\mathrm{c}=0.4 \mathrm{mM})$ and polymer 1 (PAGE-SO $\mathrm{SO}_{3} \mathrm{Na}(\mathrm{c}=0.03 \mathrm{mM})$ obtained from fitted binding isotherms, Figure S14: ITC data of adsorption of BSA $(\mathrm{c}=0.37 \mathrm{mM})$ onto polymer $2\left(\mathrm{PAGE}-\mathrm{N}^{+}\left(\mathrm{CH}_{3}\right)_{2}-\left(\mathrm{CH}_{2}\right)_{3}-\right.$ $\left.\mathrm{SO}_{3}{ }^{-}\right)$(black curves) $(\mathrm{c}=0.01 \mathrm{mM})$ with the corresponding heats of dilution (green curves) of BSA at $\mathrm{pH}=7.4, I=23 \mathrm{mM}$, Figure S15: ITC data of adsorption (black curves) of BSA $(\mathrm{c}=0.37 \mathrm{mM})$ onto polymer 3 (PAGE-NH $\left.{ }_{3} \mathrm{Cl}\right)(\mathrm{c}=0.01 \mathrm{mM})$ with the corresponding heats of dilution (red curves) of BSA at $\mathrm{pH}=7.4, I=23 \mathrm{mM}$ and (a) $\mathrm{T}=20{ }^{\circ} \mathrm{C}$, (b) $\mathrm{T}=25{ }^{\circ} \mathrm{C}$, (c) $\mathrm{T}=28{ }^{\circ} \mathrm{C}$, (d) $\mathrm{T}=30{ }^{\circ} \mathrm{C}$, (e) $T=33^{\circ} \mathrm{C}$ (f) $T=37^{\circ} \mathrm{C}$. (g) Binding isotherms corrected for the heat of dilution at $T=20$, $25,28,30,33,37^{\circ} \mathrm{C}$ and $I=23 \mathrm{mM}$, Table S4: Thermodynamic parameters of binding between BSA $(\mathrm{c}=0.37 \mathrm{mM})$ and polymer $3\left(\right.$ PAGE- $\left.\mathrm{NH}_{3} \mathrm{Cl}\right)(\mathrm{c}=0.01 \mathrm{mM})$ obtained from fitted isotherms based on a temperature series; Figure S16: ITC data of the adsorption (black curves) of BSA ( $c=0.4 \mathrm{mM}$ ) onto polymer 3 ( $\left.\mathrm{PAGE}-\mathrm{NH}_{3} \mathrm{Cl}\right)(\mathrm{c}=0.007 \mathrm{mM})$ with the corresponding heats of dilution (red curves) of BSA at $\mathrm{pH}=7.4, T=25^{\circ} \mathrm{C}$ and (a) $I=23 \mathrm{mM}$, (b) $I=35 \mathrm{mM}$, (c) $I=40 \mathrm{mM}$, (d) $I=50 \mathrm{mM}$, (e) $I=60 \mathrm{mM}$, (f) $I=70 \mathrm{mM}$, (g) $I=80 \mathrm{mM}$. (h) Binding isotherms corrected for the heat of dilution at $T=25^{\circ} \mathrm{C}$ and $I=23,35,40,50,60,70,80 \mathrm{mM}$, Table S5: Thermodynamic parameters of binding between BSA $(\mathrm{c}=0.4 \mathrm{mM})$ and polymer $3\left(\right.$ PAGE- $\left.\mathrm{NH}_{3} \mathrm{Cl}\right)(\mathrm{c}=0.007 \mathrm{mM})$ obtained from fitted isotherms based on the ionic strength series, Figure S17: ITC data of adsorption (black curves) of BSA $(c=0.37 \mathrm{mM})$ onto polymer 4 (PAGE-NH $\left.\left(\mathrm{CH}_{3}\right)_{2} \mathrm{Cl}\right)(\mathrm{c}=0.01 \mathrm{mM})$ with the corresponding heats of dilution (violet curves) of BSA at pH $=7.4, \mathrm{I}=23 \mathrm{mM}$ and (a) $\mathrm{T}=20^{\circ} \mathrm{C}$, (b) $\mathrm{T}=25^{\circ} \mathrm{C}$, (c) $\mathrm{T}=28^{\circ} \mathrm{C}$, (d) $\mathrm{T}=30^{\circ} \mathrm{C}$, (e) $\mathrm{T}=33^{\circ} \mathrm{C}$, (f) $T=37^{\circ} \mathrm{C}$. (g) Binding isotherms corrected for the heat of dilution at $T=20,25,28,30,33,37^{\circ} \mathrm{C}$ and $I=23 \mathrm{mM}$, Table S6: Thermodynamic parameters of binding between BSA $(\mathrm{c}=0.37 \mathrm{mM})$ and polymer 4 ( $\left.\mathrm{PAGE}-\mathrm{NH}\left(\mathrm{CH}_{3}\right)_{2} \mathrm{Cl}\right)(\mathrm{c}=0.01 \mathrm{mM})$ obtained from fitted isotherms based on a temperature series, Figure S18: ITC data of the adsorption (black curves) of BSA $(c=0.4 \mathrm{mM})$ onto polymer 4 (PAGE-NH $\left.\left(\mathrm{CH}_{3}\right)_{2} \mathrm{Cl}\right)(\mathrm{c}=0.01 \mathrm{mM})$ with the corresponding heats of dilution (violet curves) of BSA at $\mathrm{pH}=7.4, T=25^{\circ} \mathrm{C}$ and (a) $I=23 \mathrm{mM}$, (b) $I=35 \mathrm{mM}$, (c) $I=40 \mathrm{mM}$, (d) $I=50 \mathrm{mM}$, (e) $I=60 \mathrm{mM}$, (f) $I=70 \mathrm{mM}$, (g) $I=80 \mathrm{mM}$. (h) Binding isotherms corrected for the heat of dilution at $T=25^{\circ} \mathrm{C}$ and $I=23,35,40,50,60,70,80 \mathrm{mM}$. Table S7: Thermodynamic parameters of binding between BSA $(\mathrm{c}=0.4 \mathrm{mM})$ and polymer 4 (PAGE-NH $\left.\left(\mathrm{CH}_{3}\right)_{2} \mathrm{Cl}\right)(\mathrm{c}=0.01 \mathrm{mM})$ obtained from fitted isotherms based on the ionic strength series. Figure S19: Enthalpy-entropy compensation for the data obtained from polymer 4 (tertiary amine). (a): The blue circles denote the measured free energy of binding, whereas the blue solid line gives the respective fit by Equation (14). The solid green and red lines give the enthalpy Equation (15) and the entropy multiplied by $T$, as obtained from Equation (16), respectively. 
The respective dashed lines denote the enthalpy Equation (4) and the entropy Equation (5) deriving from the fit of Equation (7) to the experimental data. (b) The enthalpy $\Delta H_{\mathrm{b}}$ (cf. Equation (4)) obtained from the fit of the experimental data according to Equation (7) is plotted against $T \Delta S_{\mathrm{b}}$ (Equation (5)). The slope of the dashed line is 0.88 , indicating an incomplete compensation of enthalpy by entropy. See text for further explanation.

Author Contributions: Conceptualization, M.B. and M.W.; methodology, M.B. and J.J.W.; formal analysis, J.B. and M.B.; investigation, J.B., P.Y. and J.J.W.; writing-original draft preparation, M.B., J.B., P.Y. and M.W.; visualization, J.B., M.W. and M.B.; supervision, M.B. and M.W. All authors have read and agreed to the published version of the manuscript.

Funding: This research was funded by the Federal Ministry of Education and Research Germany (BMBF) [Grant number FKZ: 13N13523].

Institutional Review Board Statement: Not applicable.

Informed Consent Statement: Not applicable.

Acknowledgments: M.B. is indebted to Rainer Haag for continuous support. The publication of this article was funded through the Open Access Publication Fund of Freie Universität Berlin.

Conflicts of Interest: The authors declare no conflict of interest.

\section{References}

1. Record, M.T., Jr.; Anderson, C.F.; Lohman, T.M. Thermodynamic analysis of ion effects on the binding and con-formational equilibria of proteins and nucleic acids: The roles of ion association or release, screening, and ion effects on water activity. Q. Rev. Biophys. 1978, 11, 103-178. [CrossRef] [PubMed]

2. Datta, K. Thermodynamics of the binding of Thermus aquaticus DNA polymerase to primed-template DNA. Nucleic Acids Res. 2003, 31, 5590-5597. [CrossRef]

3. Datta, K.; LiCata, V.J. Salt Dependence of DNA binding by Thermus Aquaticus and Escherichia coli DNA Polymerases. J. Biol. Chem. 2003, 278, 5694-5701. [CrossRef]

4. Datta, K.; LiCata, V.J. Temperature dependence of DNA binding by Thermus aquaticus and Escherichia coli DNA polymerases. Biophys. J. 2003, 84, 15a.

5. Jen-Jacobson, L.; Engler, L.E.; Ames, J.T.; Kurpiewski, M.R.; Grigorescu, A. Thermodynamic Parameters of Specific and Nonspecific Protein-DNA Binding. Supramol. Chem. 2000, 12, 143-160. [CrossRef]

6. Jen-Jacobson, L.; Engler, L.E.; Jacobson, L.A. Structural and Thermodynamic Strategies for Site-Specific DNA Binding Proteins. Structure 2000, 8, 1015-1023, Erratum in 2000, 8, 3. [CrossRef]

7. Bergqvist, S.; O'Brien, R.; Ladbury, J. Site-Specific Cation Binding Mediates TATA Binding Protein-DNA Interaction from a Hyperthermophilic Archaeon. Biochemistry 2001, 40, 2419-2425. [CrossRef]

8. Bergqvist, S.; Williams, M.; O’Brien, R.; Ladbury, J.E. Heat Capacity Effects of Water Molecules and Ions at a Protein-DNA Interface. J. Mol. Biol. 2004, 336, 829-842. [CrossRef]

9. Bergqvist, S.; Williams, M.; O’Brien, R.; Ladbury, J. Halophilic adaptation of protein-DNA interactions. Biochem. Soc. Trans. 2003, 31, 677-680. [CrossRef]

10. Bergqvist, S.; Williams, M.A.; O’Brien, R.; Ladbury, J.E. Reversal of Halophilicity in a Protein-DNA Interaction by Limited Mutation Strategy. Structure 2002, 10, 629-637. [CrossRef]

11. Bergqvist, S.P.; O'Brien, R.; Ladbury, J.E. The role of solvent in a TATA box DNA-protein interaction. Biophys. J. 2000, 78, 396a.

12. Xu, X.; Angioletti-Uberti, S.; Lu, Y.; Dzubiella, J.; Ballauff, M. Interaction of Proteins with Polyelectrolytes: Comparison of Theory to Experiment. Langmuir 2019, 35, 5373-5391. [CrossRef] [PubMed]

13. Achazi, K.; Haag, R.; Ballauff, M.; Dernedde, J.; Kizhakkedathu, J.N.; Maysinger, D.; Multhaup, G. Understanding the Interaction of Polyelectrolyte Architectures with Proteins and Biosystems. Angew. Chem. Int. Ed. 2021, 60, 3882-3904. [CrossRef] [PubMed]

14. Kayitmazer, A.B.; Quinn, B.; Kimura, K.; Ryan, G.L.; Tate, A.J.; Pink, D.A.; Dubin, P.L. Protein Specificity of Charged Sequences in Polyanions and Heparins. Biomacromolecules 2010, 11, 3325-3331. [CrossRef] [PubMed]

15. Kayitmazer, A.B.; Seeman, D.; Minsky, B.B.; Dubin, P.L.; Xu, Y. Protein-polyelectrolyte interactions. Soft Matter 2013, 9, 2553-2583. [CrossRef]

16. Kayitmazer, A.B. Thermodynamics of complex coacervation. Adv. Colloid Interface Sci. 2017, 239, 169-177. [CrossRef] [PubMed]

17. de Kruif, C.G.; Weinbreck, F.; de Vries, R. Complex coacervation of proteins and anionic polysaccharides. Curr. Opin. Colloid Interface Sci. 2004, 9, 340-349. [CrossRef]

18. Ball, V.; Winterhalter, M.; Schwinte, P.; Lavalle, P.; Voegel, J.-C.; Schaaf, P. Complexation Mechanism of Bovine Serum Albumin and Poly(allylamine hydrochloride). J. Phys. Chem. B 2002, 106, 2357-2364. [CrossRef]

19. Yu, S.; Xu, X.; Yigit, C.; van der Giet, M.; Zidek, W.; Jankowski, J.; Dzubiella, J.; Ballauff, M. Interaction of human serum albumin with short polyelectrolytes: A study by calorimetry and computer simulations. Soft Matter 2015, 11, 4630-4639. [CrossRef] 
20. Wei, Q.; Becherer, T.; Angioletti-Uberti, S.; Dzubiella, J.; Wischke, C.; Neffe, A.; Lendlein, A.; Ballauff, M.; Haag, R. Protein Interactions with Polymer Coatings and Biomaterials. Angew. Chem. Int. Ed. 2014, 53, 8004-8031. [CrossRef]

21. Weinhart, M.; Grunwald, I.; Wyszogrodzka, M.; Gaetjen, L.; Hartwig, A.; Haag, R. Linear Poly(methyl glycerol) and Linear Polyglycerol as Potent Protein and Cell Resistant Alternatives to Poly(ethylene glycol). Chem. Asian J. 2010, 5, $1992-2000$. [CrossRef]

22. Marquardt, F.; Stöcker, C.; Gartzen, R.; Heine, E.; Keul, H.; Möller, M. Novel antibacterial polyglycidols: Relationship between structure and properties. Polymers 2018, 10, 96. [CrossRef]

23. Heinen, S.; Cuéllar-Camacho, J.L.; Weinhart, M. Thermoresponsive poly(glycidyl ether) brushes on gold: Surface engineering parameters and their implication for cell sheet fabrication. Acta Biomater. 2017, 59, 117-128. [CrossRef] [PubMed]

24. Stöbener, D.D.; Hoppensack, A.; Scholz, J.; Weinhart, M. Endothelial, smooth muscle and fibroblast cell sheet fabrication from self-assembled thermoresponsive poly(glycidyl ether) brushes. Soft Matter 2018, 14, 8333-8343. [CrossRef] [PubMed]

25. Thomas, A.; Müller, S.S.; Frey, H. Beyond Poly(ethylene glycol): Linear Polyglycerol as a Multifunctional Polyether for Biomedical and Pharmaceutical Applications. Biomacromolecules 2014, 15, 1935-1954. [CrossRef] [PubMed]

26. Bochenek, M.; Oleszko-Torbus, N.; Wałach, W.; Lipowska-Kur, D.; Dworak, A.; Utrata-Wesołek, A. Polyglycidol of Linear or Branched Architecture Immobilized on a Solid Support for Biomedical Applications. Polym. Rev. 2020, 60, 1-51. [CrossRef]

27. Wen, J.; Weinhart, M.; Lai, B.; Kizhakkedathu, J.; Brooks, D.E. Reversible hemostatic properties of sulfabetaine/quaternary ammonium modified hyperbranched polyglycerol. Biomaterials 2016, 86, 42-55. [CrossRef]

28. Kuhlmann, M.; Reimann, O.; Hackenberger, C.P.R.; Groll, J. Cysteine-Functional Polymers via Thiol-ene Conjugation. Macromol. Rapid Commun. 2015, 36, 472-476. [CrossRef]

29. Merlot, A.M.; Kalinowski, D.S.; Richardson, D.R. Unraveling the mysteries of serum albumin-More than just a serum protein. Front. Physiol. 2014, 5, 299. [CrossRef]

30. Indyk, L.; Fisher, H.F. Theoretical aspects of isothermal titration calorimetry. Methods Enzymol. 1998, 295, 350-364. [CrossRef]

31. Ran, Q.; Xu, X.; Dey, P.; Yu, S.; Lu, Y.; Dzubiella, J.; Haag, R.; Ballauff, M. Interaction of human serum albumin with dendritic polyglycerol sulfate: Rationalizing the thermodynamics of binding. J. Chem. Phys. 2018, 149, 163324. [CrossRef] [PubMed]

32. Walkowiak, J.; Lu, Y.; Gradzielski, M.; Zauscher, S.; Ballauff, M. Thermodynamic Analysis of the Uptake of a Protein in a Spherical Polyelectrolyte Brush. Macromol. Rapid Commun. 2019, 41, e1900421. [CrossRef] [PubMed]

33. Walkowiak, J.J.; Ballauff, M.; Zimmermann, R.; Freudenberg, U.; Werner, C. Thermodynamic Analysis of the Interaction of Heparin with Lysozyme. Biomacromolecules 2020, 21, 4615-4625. [CrossRef]

34. Walkowiak, J.J.; Ballauff, M. Interaction of Polyelectrolytes with Proteins: Quantifying the Role of Water. Adv. Sci. 2021, 8, 2100661. [CrossRef] [PubMed]

35. Manning, G.S. Limiting Laws and Counterion Condensation in Polyelectrolyte Solutions I. Colligative Properties. J. Chem. Phys. 1969, 51, 924-933. [CrossRef]

36. Manning, G.S. Limiting Laws and Counterion Condensation in Polyelectrolyte Solutions II. Self-Diffusion of the Small Ions. J. Chem. Phys. 1969, 51, 934-938. [CrossRef]

37. Manning, G.S. Limiting Laws and Counterion Condensation in Polyelectrolyte Solutions. III. An Analysis Based on the Mayer Ionic Solution Theory. J. Chem. Phys. 1969, 51, 3249-3252. [CrossRef]

38. Tanford, C. Extension of the theory of linked functions to incorporate the effects of protein hydration. J. Mol. Biol. 1969, 39, 539-544. [CrossRef]

39. Meulen, K.A.V.; Saecker, R.M.; Record, M.T. Formation of a Wrapped DNA-Protein Interface: Experimental Characterization and Analysis of the Large Contributions of Ions and Water to the Thermodynamics of Binding IHF to H' DNA. J. Mol. Biol. 2008, 377, 9-27. [CrossRef] [PubMed]

40. Record, M.T.; Guinn, E.; Pegram, L.; Capp, M. Introductory Lecture: Interpreting and predicting Hofmeister salt ion and solute effects on biopolymer and model processes using the solute partitioning model. Faraday Discuss. 2012, 160, 9-44. [CrossRef] [PubMed]

41. Brocas, A.-L.; Cendejas, G.; Caillol, S.; Deffieux, A.; Carlotti, S. Controlled synthesis of polyepichlorohydrin with pendant cyclic carbonate functions for isocyanate-free polyurethane networks. J. Polym. Sci. Part A Polym. Chem. 2011, 49, 2677-2684. [CrossRef]

42. Gervais, M.; Brocas, A.-L.; Cendejas, G.; Deffieux, A.; Carlotti, S. Synthesis of Linear High Molar Mass Glycidol-Based Polymers by Monomer-Activated Anionic Polymerization. Macromolecules 2010, 43, 1778-1784. [CrossRef]

43. Lowe, A. Thiol-ene "click" reactions and recent applications in polymer and materials synthesis: A first update. Polym. Chem. 2014, 5, 4820-4870. [CrossRef]

44. Ha, J.-H.; Spolar, R.S.; Record, M. Role of the hydrophobic effect in stability of site-specific protein-DNA complexes. J. Mol. Biol. 1989, 209, 801-816. [CrossRef]

45. Liu, Y.; Sturtevant, J.M. Significant discrepancies between van't Hoff and calorimetric enthalpies. III. Biophys. Chem. 1997, 64, 121-126. [CrossRef]

46. Xu, X.; Ballauff, M. Interaction of Lysozyme with a Dendritic Polyelectrolyte: Quantitative Analysis of the Free Energy of Binding and Comparison to Molecular Dynamics Simulations. J. Phys. Chem. B 2019, 123, 8222-8231. [CrossRef]

47. Chen, S.; Li, L.; Zhao, C.; Zheng, J. Surface hydration: Principles and applications toward low-fouling/nonfouling biomaterials. Polym. 2010, 51, 5283-5293. [CrossRef] 
48. Shaoyi, J.; Jiang, S. Molecular Understanding and Design of Zwitterionic Materials. Adv. Mater. 2015, 27, 15-26. [CrossRef] [PubMed]

49. Chen, S.; Zheng, J.; Li, L.; Jiang, S. Strong Resistance of Phosphorylcholine Self-Assembled Monolayers to Protein Adsorption: Insights into Nonfouling Properties of Zwitterionic Materials. J. Am. Chem. Soc. 2005, 127, 14473-14478. [CrossRef] [PubMed]

50. Chen, S.; Yu, F.; Yu, Q.; He, A.Y.; Jiang, S. Strong Resistance of a Thin Crystalline Layer of Balanced Charged Groups to Protein Adsorption. Langmuir 2006, 22, 8186-8191. [CrossRef] 